\title{
The Role of Smoking-Induced Alterations of Soluble Intercellular Adhesion Molecules in the Development of Chronic Obstructive Pulmonary Disease
}

DOI: 10.17691/stm2015.7.4.14

Received April 7, 2015

E.V. Makarova, MD, PhD, Associate Professor, Department of Internal Diseases Propedeutics

Nizhny Novgorod State Medical Academy, 10/1 Minin and Pozharsky Square, Nizhny Novgorod, 603005, Russian Federation

The aim of the investigation was to study the alterations in the serum level of soluble intercellular adhesion molecules (sICAM) under the influence of smoking and to assess the role of the revealed impairment in the formation and development of chronic obstructive pulmonary disease (COPD).

Materials and Methods. The study included 82 smokers ( 24 women and 58 men aged 19 to 72 years) and 52 healthy non-smoking donors (17 women and 35 men aged 20 to 57 years). The smokers were divided into the following groups: 1) smokers with normal lung function (mean smoking index of $11.2 \pm 4.3$ pack-years) -32 patients; 2) smokers with airflow limitation (COPD patients) with smoking index of $<30$ packyears - 17 patients; 3 ) smokers having airflow limitation (COPD patients) with smoking index of $\geqslant 30$ pack-years -33 patients. The subjects underwent clinical examination, CAT test, assessment of dyspnea (mMRC) and smoking index (pack-years), pulmonary function test (PFT), chest radiography, microscopic and microbiological examination of sputum. The serum level of soluble intercellular adhesion antigens sICAM-3 (sCD50) total and sICAM-1 (sCD54) total and oligomer were determined by enzyme immunoassay.

Results. The smokers of group 1 were found to have elevated levels of sCD54 antigens (oligomer and total) and sCD50 compared to nonsmoking donors, which may reflect a stimulatory effect of tobacco smoke on cell migration into the inflammation focus. Total sCD54 antigen was higher in smoking COPD patients of group 2 than that of the donor group. There was a decrease in all tested molecules in heavy smokers, COPD patients (group 3), compared to both the control and group 2. There was found a negative correlation between the serum level of sCD50 and smoking index, as well as positive a correlation between the level of total SCD54 and PFT parameters. Smoking intensity affected COPD progression. In group 3 the patients had higher mMRC dyspnea index and CAT test score; they had more exacerbations during a year, more frequent application of systemic corticosteroids and antibiotics than the patients in other groups.

Conclusion. The revealed smoking-induced alterations in the network of soluble intercellular adhesion molecules contribute to the formation and progression of obstructive disorders and chronic inflammation in COPD. Low level of soluble adhesion molecules is a marker of severe COPD with frequent exacerbations.

Key words: chronic obstructive pulmonary disease; COPD; soluble intercellular adhesion molecules; sICAM-1; sICAM-3; smoking.

Growth of chronic obstructive pulmonary disease (COPD) incidence and the resulting death rate largely depend on the increasing significance of risk factors, one of which is smoking. According to the World Health Organization, $22 \%$ of the world adult population smoke and there is $39.1 \%$ of smokers in Russia. Smoking causes 6 million deaths annually [1].

The damaging mechanisms of tobacco smoke are various. Bone-marrow hemopoiesis stimulation is especially important among them, as it leads to increasing number of immature neutrophils in both systemic circulation and pulmonary vessels, and neutrophil infiltration of lungs in smokers is a well-known phenomenon [2].

Intercellular adhesion molecules, ICAM-1 and ICAM-3, expressed on leukocytes, epithelial, quiescent endothelial and other cells play a central role in the initial implementation of neutrophil migration to the inflammation focus [3]. Inflammatory mediators, oxidative stress and other factors stimulate expression of adhesion molecules.

Soluble adhesion molecules (s-forms) resulting from proteolytic shedding or alternative DNA splicing are functionally active along with the membrane forms of adhesion molecules. In pathological conditions not only the expression of membrane ICAM-1 and ICAM-3 is impaired but the content of their soluble forms in biological fluids as well [4]. In COPD soluble ICAM-1 is also considered to be one of the disease biomarkers. However, smoking status is often disregarded in research works despite the significance of this factor in COPD pathogenesis. The given factor causes the necessity of evaluation of sICAM-1 significance with regard to tobacco smoke impact on the level of adhesion molecules.

The aim of the investigation was to study the alterations in the serum level of soluble intercellular

For contacts: Makarova Ekaterina Vadimovna, e-mail: e_makarowa@mail.ru 
adhesion molecules under the influence of smoking and to assess the role of the revealed impairment in the formation and development of chronic obstructive pulmonary disease.

Materials and Methods. The study was performed on the basis of City Clinical Hospital No.10, Nizhny Novgorod. It included 82 smokers (24 women and 58 men aged 19 to 72 years) and 52 healthy non-smoking donors (17 women and 35 men aged 20 to 57 years). The study was carried out in accordance with Declaration of Helsinki (adopted in June 1964 (Helsinki, Finland) and revised in October 2000 (Edinburgh, Scotland)) and was performed following approval by the Ethics Committee of City Clinical Hospital No.10. Informed consent was received from every patient.

Smokers were divided as follows: group 1: smokers with normal lung function (32 patients, modified Tiffeneau index $\geqslant 0.7$ ); group 2: smokers with airflow limitation (17 COPD patients, modified Tiffeneau index $<0.7$, smoking index of $<30$ pack-years); group 3: smokers having airflow limitation (33 COPD patients with modified Tiffeneau index $<0.7$, smoking index of $\geqslant 30$ pack-years). Thirty COPD patients had spirometric GOLD stage II, 20 patients had GOLD stage III, all of them were reported to have stable stage of the disease. The study included no patients who had acute exacerbation of COPD and received systemic glucocorticoids (GC) or antibiotics in the last 6 weeks as well as those who suffered acute respiratory infections with antibacterial therapy in the last 4 weeks prior to the study. Besides, exclusion criteria comprised bronchial asthma, tuberculosis, bronchiectatic disease and other respiratory diseases; any malignant disorders, connective tissue diseases, decompensated diseases of heart, liver, kidneys, acute coronary syndrome, acute respiratory viral infections and other conditions that could affect the study results.

COPD patients received therapy according to the standards of delivering medical care to adult population. All COPD patients in stable condition received longand short - acting bronchodilators, 32\% of patients inhaled steroid GC; systemic GC, antibiotics, mucolytics and other preparations were instituted on therapeutic grounds in the exacerbation phase.

All smokers and non-smoking donors along with clinical examination underwent pulmonary function test (PFT) using MicroLab spirograph (Micro Medical, England). We assessed the following postbronchodilator indexes: forced expiratory volume per $1 \mathrm{~s}$ (FEV1), modified Tiffeneau index (FEV1/forced vital capacity (FVC) ratio), maximum expiratory flow (MEF50 and MEF75).

Smoking index was calculated in smokers (packyears). COPD patients completed CAT test [5]. We assessed dyspnea intensity with a modified questionnaire of the British Medical Research Council (mMRC) [5] as well as the number of exacerbations in the last 12 months. Also performed were chest radiography, microscopic and microbiological examination of sputum.

The serum level of soluble intercellular adhesion antigens SCD50 total (sICAM-3), SCD54 total and oligomer (sICAM-1) were determined in all smokers and non-smoking donors by enzyme immunoassay with monoclonal antibodies of ICO series against CD50, CD54 and polyclonal antibodies against mononuclear cell antigens of human peripheral blood. The study of serum antigens was carried out in the Institute of Molecular Biology and Biomedicine, Lobachevsky State University of Nizhni Novgorod.

The obtained results are presented as mean value and standard deviation $(\mathrm{M} \pm \mathrm{SD})$ with normal distribution or as a median and percentiles ( $\mathrm{Me}$ [25p; 75p]) when deviation differs from normal. Statistical analysis was performed using Pirson criterion, Student's t-test, Mann-Whitney Utest, Spearman's rank-correlation coefficient. The results were mathematically processed with statistical software package Statistica 6.0.

\section{Results}

Clinical profile of smokers with normal and impaired external respiration function. Since nociinfluence of smoking has a cumulative character, in the group of smokers with normal PFT the average age and smoking index appeared to be less than in those having airflow limitation (Table 1). In group 1 smoking index was

Table 1

Characteristics of smokers with normal lung function and airflow limitation (MESD)

\begin{tabular}{|lccc}
\hline \multicolumn{1}{c}{ Indexes } & $\begin{array}{c}\text { Smokers with normal PFT } \\
\text { (group 1, } \mathbf{n = 3 2 )}\end{array}$ & $\begin{array}{c}\text { Smoking COPD patients } \\
\text { (groups 2 and 3, } \mathbf{n = 5 0 )}\end{array}$ & p \\
\hline Women/men & $10 / 22$ & $14 / 36$ & - \\
\hline Age (years) & $28 \pm 6$ & $62 \pm 10$ & 0.00001 \\
\hline Smoking index (pack-years) & $11.2 \pm 4.3$ & $31 \pm 12$ & 0.00001 \\
\hline COPD duration (years) & - & $17 \pm 7$ & - \\
\hline FEV1 (\% of normal) & $91.0 \pm 3.3$ & $55 \pm 6$ & 0.00001 \\
\hline FEV1/FVC (\% of normal) & $117.0 \pm 6.4$ & $65 \pm 8$ & 0.00001 \\
\hline
\end{tabular}


Table 2

Characteristics of groups of smoking COPD patients

\begin{tabular}{|c|c|c|c|}
\hline Indexes & $\begin{array}{c}\text { Smoking index <30 } \\
\text { pack-years } \\
\text { (group 2, n=17) }\end{array}$ & $\begin{array}{c}\text { Smoking index } \geqslant 30 \\
\text { pack-years } \\
\text { (group } 3, n=33 \text { ) }\end{array}$ & $\mathbf{p}$ \\
\hline \multicolumn{4}{|c|}{ Clinical profile } \\
\hline Smoking index (pack-years) & $20[16 ; 25]$ & $38[33 ; 45]$ & 0.0001 \\
\hline COPD duration (years) & $10[10 ; 20]$ & $20[10 ; 30]$ & 0.13 \\
\hline Number of exacerbations per year & $1.3 \pm 0.5$ & $2.3 \pm 0.7$ & 0.0009 \\
\hline $\begin{array}{l}\text { General length of hospitalization } \\
\text { for exacerbations during a year (days) }\end{array}$ & $19.5 \pm 2.3$ & $39.1 \pm 2.8$ & 0.03 \\
\hline CAT test (score) & $11.0 \pm 2.2$ & $21.7 \pm 5.1$ & 0.002 \\
\hline $\begin{array}{l}\text { Dyspnea, } \geqslant 3 \text { points according to mMRC } \\
\text { ( } \% \text { of patients) }\end{array}$ & 60 & 85 & 0.048 \\
\hline \multicolumn{4}{|c|}{ Stable phase therapy } \\
\hline M-cholinergic antagonists (\% of patients) & 53 & 61 & 0.69 \\
\hline$\beta$-agonists ( $\%$ of patients) & 76 & 78 & 0.79 \\
\hline Inhalant GC ( $\%$ of patients) & 18 & 39 & 0.13 \\
\hline \multicolumn{4}{|c|}{ Exacerbation therapy } \\
\hline $\begin{array}{l}\text { Courses of systemic GC in the previous year } \\
\text { (\% of patients) }\end{array}$ & 10 & 53 & 0.04 \\
\hline $\begin{array}{l}\geqslant 2 \text { of antibiotic courses in the previous year } \\
\text { (\% of patients) }\end{array}$ & No & 30 & 0.01 \\
\hline
\end{tabular}

Table 3

Pulmonary function test in smokers, COPD patients

\begin{tabular}{|lccc}
\hline \multicolumn{1}{c}{ Indexes } & $\begin{array}{c}\text { Smoking index }<30 \text { pack-years } \\
\text { (group } \mathbf{2 , n = 1 7 )}\end{array}$ & $\begin{array}{c}\text { Smoking index } \geqslant \mathbf{3 0} \text { pack-years } \\
\text { (group } \mathbf{3}, \mathbf{n}=\mathbf{3 3} \text { ) }\end{array}$ & $\mathbf{p}$ \\
\hline FEV1 $(\%$ of normal) & $70[54 ; 79]$ & $49[38 ; 64]$ & 0.03 \\
\hline MEF50 (\% of normal) & $53[43 ; 57]$ & $23[16 ; 31]$ & 0.02 \\
\hline MEF75 (\% of normal) & $36[15 ; 53]$ & $24[18 ; 49]$ & 0.8 \\
\hline
\end{tabular}

2-14 pack-years, while in smoking COPD patients it varied from 12 to 53 pack-years.

Clinical profile of COPD patients with different smoking index. Smoking intensity affects COPD progression (Table 2). In smokers with smoking index of $\geqslant 30$ pack-years more exacerbations have been reported during the previous year, including moderate and severe cases requiring systemic GC therapy and/or hospitalization. They received antibacterial preparations to treat exacerbations more often.

The patients of group 3 were found to have higher dyspnea values and total CAT test score at the time of examination, more frequent radiologic abnormalities in the lungs (in $45 \%$ of patients from group 2 and $78 \%$ from group 3; $p=0.02$ ).

PFT indexes also differed in the groups of smokers with COPD (Table 3). The patients with a longer smoking term were found to have lower FEV1 and MEF50 values as compared to the group of COPD patients with smoking index of $<30$ pack-years. Significant purulence and bacterial load was characteristic of these patients' sputum (Table 4). Thus, high smoking intensity correlated with less favorable disease progression, frequent recurrences, marked PFT abnormalities.

The serum level of soluble intercellular adhesion molecules in smokers. The study of soluble intercellular adhesion molecules serum level in smokers with normal lung function revealed statistically significant elevation of SCD50 and SCD54 antigens, total and oligomer, compared to non-smoking donors (Table 5).

The level of soluble intercellular adhesion molecules in smokers, COPD patients, differed depending on the 
Table 4

The results of microscopic and microbiological analysis of sputum

\begin{tabular}{lccc}
\hline \multicolumn{1}{c}{ Indexes } & $\begin{array}{c}\text { Smoking index } \\
<30 \text { pack-years } \\
\text { (group 2, } \mathbf{n = 1 7 )}\end{array}$ & $\begin{array}{c}\text { Smoking index } \\
\geqslant 30 \text { pack-years } \\
\text { (group 3, } \mathbf{n = 3 3 )}\end{array}$ & $\mathbf{p}$ \\
\hline Sputum neutrophils & $7[1 ; 26]$ & $40[12 ; 100]$ & 0.02 \\
\hline Number of microorganism types & $2[1 ; 3]$ & $3[2 ; 4]$ & 0.11 \\
\hline Microbial associations $(\%$ of patients) & 59 & 85 & 0.54 \\
\hline Total number CFU/ml $\left(\times 10^{6}\right)$ & $0.04[0.003 ; 70]$ & $39[1.3 ; 170]$ & 0.016 \\
\hline
\end{tabular}

Ta ble 5

The serum level of soluble intercellular adhesion molecules in smokers and non-smoking donors

\begin{tabular}{|c|c|c|c|c|c|}
\hline \multirow{2}{*}{ Antigen } & \multirow{2}{*}{$\begin{array}{l}\text { Non-smoking donors } \\
\qquad(\mathrm{n}=52)\end{array}$} & \multicolumn{3}{|c|}{ Smokers } & \multirow{2}{*}{$\begin{array}{c}\text { p (between } \\
\text { groups } 2 \text { and 3) }\end{array}$} \\
\hline & & Group 1 (n=32) & Group 2 ( $n=17)$ & Group 3 (n=33) & \\
\hline sCD54 total & $64[58 ; 69]$ & $85[75 ; 112]^{*}$ & $73[63 ; 109]^{*}$ & $55[10 ; 64]^{*}$ & 0.002 \\
\hline sCD54 olligomer & $149[134 ; 158]$ & $156[126 ; 551]^{*}$ & 115 [98; 213] & $67[39 ; 77]^{*}$ & 0.04 \\
\hline sCD50 & 362 [341; 413] & $464[362 ; 652]^{*}$ & $309[285 ; 456]$ & $263[216 ; 287]^{*}$ & 0.01 \\
\hline
\end{tabular}

* statistical significance of value differences in comparison with healthy donors, $p<0.05$.

extent of tobacco exposure. In the patients of group 2 (with smoking index of less than 30 pack-years) total sCD54 antigen level was statistically significantly higher, yet SCD54 dimer and SCD50 antigen levels were the same as in non-smoking donors. At the same time, the serum concentrations of sCD54 antigens, total and oligomer, and SCD50 were statistically significantly lower in patients with tobacco exposure of more than 30 pack-years in contrast to both non-smoking donors and smokers from group 2. Decrease in soluble intercellular adhesion molecules by more than 1 standard deviation (1SD) as compared to donors was reported in $64 \%$ of patients in group 3 .

Correlation between the level of soluble intercellular adhesion molecules, smoking index and pulmonary function test. There was revealed a correlation between SCD50 serum level and smoking intensity $(R=-0.43 ; p=0.04)$. There was also found a correlation between total $\mathrm{SCD} 54$ antigen level and PFT indexes in smoking COPD patients: FEV1 $(\mathrm{R}=0.6$; $\mathrm{p}=0.02)$, MEF50 ( $\mathrm{R}=0.56 ; \mathrm{p}=0.04)$ and MEF75 ( $\mathrm{R}=0.64$; $\mathrm{p}=0.03$ ); their CAT test index correlated with FVC $(R=0.35 ; p=0.02)$.

The obtained results prove the influence of intensive long-term tobacco exposure on the immune response and the level of intercellular adhesion molecules in particular. In its turn, the imbalance in adhesion molecule networks is associated with bronchial patency impairment.

Discussion. Pathogenic connection of COPD and smoking has been well studied. Smokers with COPD have been previously shown $[6,7]$ to have alterations in a wide range of soluble differentiating leucocyte molecules, including adhesion molecules. Participation of smoking- induced adhesion impairments in COPD pathogenesis has been actively discussed in the literature. According to a number of authors, smoking affects both expression of adhesion molecules by leukocytes, endothelial and epithelial lung cells $[8,9]$ and release of the soluble variants [10]. Other sources argue that dysregulation in the system of adhesion molecules is characteristic of COPD itself regardless of smoking status [11].

According to our data, smoking has a profound influence on the level of soluble adhesion molecules. The smokers with normal lung function under the study were found to have high level of SICAM-1 and sICAM-3 antigens in comparison with non-smoking healthy subjects. This is consistent with the findings of most authors who also show elevation of SICAM- 1 level in biological fluids due to cumulative effect of smoking [10], including passive smoking. In COPD patients with smoking index of no more than 30 pack-years elevation of total sICAM-1 antigen was revealed as well. High serum level of soluble adhesion molecules in smokers with both normal and impaired lung function as well as a correlation between smoking intensity and SICAM-3 concentration provide evidence that smoking-induced alterations in adhesion molecule networks participate in COPD inflammation pathogenesis.

Smoking is known to enhance ICAM- $1 / \beta 2$-integrindependent recruitment of inflammation cells to the lungs $[12,13]$. Neutrophil infiltration of the lungs, typical of smokers, is also an inflammation substrate in COPD. Participation of cellular adhesion molecules in inflammation development is the subject of intensive research nowadays [14]. ICAM-1 is known to provide cellular interaction stability, endothelial transmigration of 
leukocytes and T-lymphocytes $[15,16]$. Recently ICAM-1 has been described as a receptor for cellular intrusion of human rhinovirus [17], which is known to be a frequent cause of COPD exacerbation. Adhesion molecules interfere with different immune and inflammatory processes [18]. The role of ICAM- 1 in transmitting signals has also been discussed [14]. It has been shown that ICAM-1 gene expression is elevated in COPD patients [19], and ICAM-1 pulmonary expression blockage reduces pulmonary injury in induced pancreatitis [20].

Soluble adhesion molecules exert their biological influence either by competitive inhibition of cellular interaction, or by adhesion to the appropriate cell surface ligand to initiate response, they also have immunomodulatory properties relating to basic pathological processes. Thus, various effects of both membrane and SICAM-1 promote development of smoking-induced pathology, including COPD, malignant, cardiovascular and other diseases [21].

A great number of researchers report the elevated sICAM-1 concentration to be related to cardiovascular pathology and the risk of vascular catastrophes [22, 23]. Besides, high level of sICAM-1 has been reported in patients with lung cancer and other proliferative diseases [24, 25]. In general population SICAM-1 dynamic concentration growth is a marker of progressing pulmonary emphysema and declining pulmonary function [26], and in pneumonoconiosis patients the serum level of ICAM- 1 is considered to be a biomarker of massive pulmonary fibrosis [27]. Other authors' findings confirm that in progressing COPD apart from decrease in the relative number of $\mathrm{CD} 54^{+}$and $\mathrm{CD}_{5} 0^{+}$mononuclear cells in the peripheral blood and induced sputum the level of sCD54 and SCD50 antigens elevates, which correlates with growing bronchial obstruction [7].

In the presence of COPD various factors may affect the concentration of soluble adhesion molecules. While in smokers with normal PFT sICAM-1 level was elevated, in COPD patients with increasing tobacco exposure we observed decrease in the level of soluble adhesion molecules. Marked decrease in adhesion molecule concentration correlated with a more severe COPD course (considering dyspnea index, CAT test and the degree of pulmonary function impairment), as well as more frequent exacerbations, both moderate and severe, requiring antibiotics and systemic GC, or hospitalization.

Pharmacotherapy, in its turn, may influence the level of soluble adhesion molecules. So, macrolide antibiotics frequently used to treat respiratory infections have been proved to inhibit ICAM-1 production and block the release of sICAM-1 by bronchial epithelium, which is seen as an immunomodulatory effect of macrolides that promotes neutrophilous inflammation resolution [28]. Accordingly, in a number of patients of group 3 low sICAM level can be attributed to frequent courses of antibacterial therapy. However, there are insufficient data in the literature showing the effect of other antibacterial preparations, indicated in COPD exacerbation, on adhesion molecule balance. Moreover, the patients receiving antibiotics during the previous four weeks were not included in this study.

Another factor possibly affecting adhesion molecule levels is corticosteroid therapy. GC are known to suppress the transcription of adhesion molecule genes. Lower ICAM-1 expression is a mechanism of antiinflammatory effect of GC and leads to the reduction of cell migration to the inflammation focus [29]. The studied patients of group 3 with markedly low level of soluble adhesion molecules received repeated short courses of systemic GC for exacerbation treatment 5 times more often in the previous year compared to the patients of group 2 whose sCD54 and sCD50 levels were normal or elevated. We have already underlined the decrease in soluble adhesion molecule levels while treating COPD exacerbations with systemic GC and antibiotics [30]. To level these effects our study included stable COPD patients receiving no systemic GC over the previous six weeks.

On the other hand, many patients were treated with combined preparations, including inhalant GC. In some cases topical hormones can influence induced cellular adhesion molecule expression in the inflammation focus as well [31]. However, systemic effects of topical hormones are expressed insignificantly [32]. In our study the frequency of inhalant GC administration was not significantly different in COPD patients of group 2 and 3 having differences in soluble adhesion molecule levels. Besides, the problem of inhalant GC impact on the serum level of soluble leukocyte differentiation molecules requires separate study.

Additionally, when evaluating the investigation results in smoking COPD patients, it is necessary to take into account such well-known clinical phenomenon as steroid-resistance, which shows itself on the cell level (in vitro investigations) by the absence of adequate alveolar macrophage response of COPD patients to corticosteroid hormones. In COPD even peroral GC insufficiently inhibit neutrophilous inflammation, cytokine release in the airways and inflammation mediator gene expression (including adhesion molecules), which they silence in normal conditions. Resistance to normal GC effect in COPD (in contrast to bronchial asthma) is caused by inhibiting influence of tobacco smoking and oxidative stress on histone deacetylase (HDAC) playing an essential role in gene expression regulation [33]. Experimental data show that histone acetylation/ deacetylation enzymes themselves play a significant role in regulation of inflammatory molecules, including ICAM-1 [34].

Other preparations widely used for COPD treatment ( $\beta$-agonists, tiotropium, ambroxol) can reduce adhesion molecule expression as well [35-37], but there were no differences between groups of COPD patients as to the frequency of using these preparations. 
Therapeutic effects cannot be responsible for the imbalance in adhesion molecule networks in all studied subjects. We have to look for other mechanisms responsible for the decrease of soluble adhesion molecule level apart from GC and antibiotic effects. In this connection, the role of immune mechanism exhaustion and cellular interaction impairment under the influence of oxidative stress and chronic respiratory inflammation should not be disregarded. Thus, low level of adhesion molecules in some COPD patients can be a consequence of pharmacotherapy (corticosteroid, antibacterial) and a property of the disease associated with long-term smoking.

It can be suggested that decreased serum concentration of soluble adhesion molecules results from compromised shedding and consequently impaired expression of membrane forms, which leads to the limitation of cell migration. Cell migration impairment can have different consequences for the patient. On the one hand, compromised migration is a way of causing extremely destructive effect of neutrophils on the lung tissue. On the other hand, suppression of active leukocyte migration to the inflammation focus makes effective management of inflammation agent complicated. This has been confirmed by experimental data obtained on a mice model of COPD/elastase-induced pulmonary emphysema [38]. Epithelial ICAM-1 membrane expression was found to be significantly reduced in these mice, which was accompanied by pulmonary clearance impairment of Haemophilus influenza, one of the most frequent bacterial COPD agents. This confirms the hypothesis of ICAM-1 promoting bacterial agent clearance and may account for high bacterial load of bronchial mucous in our patients having low concentration of soluble adhesion molecules.

Consistently, this category of patients is characterized by more frequent disease recurrences, the reason of which is bacterial infection in $50-60 \%$ of cases [39]. Intense therapy in the exacerbation period, for example, antibiotics and systemic GC administration, promotes intercellular adhesion impairment in COPD patients closing the "vicious" circle.

Thus, smoking causes essential impairment in the system of soluble adhesion molecules participating in the development of an inflammatory process in the respiratory tract. In smokers with normal lung function and average smoking index of $11.2 \pm 4.3$ pack-years the serum level of soluble adhesion molecules SCD50 and sCD54 (total and oligomer) is elevated, which may reflect the stimulating effect of tobacco smoke on the process of cell migration to the inflammation focus. In smokers suffering from COPD the serum level of soluble adhesion molecules decreases compared to beginning smokers, which may speak of immune mechanism exhaustion and cellular interaction impairment.

The extent of tobacco exposure correlates with the intensity of decrease in the level of circulating SCD50 in COPD. The lowest serum level of soluble intercellular adhesion molecules (sCD54, sCD50) is characteristic of patients with a smoking index of $\geq 30$ pack-years and is associated with more marked airflow limitation, more severe COPD progression, a tendency to more frequent exacerbations, including administration of systemic GC and antibiotics.

Conclusion. Smoking-induced alterations to the network of soluble intercellular adhesion molecules are involved in the formation and progression of chronic inflammation and obstructive disorders in COPD. Low level of soluble intercellular adhesion molecules is a marker of severe COPD progression with frequent exacerbations.

Study Funding and Conflicts of interest. This study was not supported by any financial sources, and there is no conflicts of interest associated with this study.

\section{References}

1. WHO report on the global tobacco epidemic 2013. URL: $\quad$ http://apps.who.int/iris/bitstream/10665/85380/1/ 9789241505871_eng.pdf.

2. Gane J., Stockley R. Mechanisms of neutrophil transmigration across the vascular endothelium in COPD. Thorax 2012; 67(6): 553-561, http://dx.doi.org/10.1136/thoraxjnl-2011200088.

3. Muller W.A. Mechanisms of leukocyte transendothelial migration. Annu Rev Pathol 2011; 6: 323-344, http://dx.doi. org/10.1146/annurev-pathol-011110-130224.

4. Hollander C., Sitkauskiene B., Sakalauskas R., Westin U., Janciauskiene S.M. Serum and bronchial lavage fluid concentrations of IL-8, SLPI, SCD14 and SICAM-1 in patients with COPD and asthma. Respir Med 2007; 101(9): 1947-1953, http://dx.doi.org/10.1016/j.rmed.2007.04.010.

5. Global'naya strategiya diagnostiki, lecheniya i profilaktiki khronicheskoy obstruktivnoy bolezni legkikh (peresmotr 2011 g.) [Global strategy of diagnosis, treatment and prevention of chronic obstructive pulmonary disease (revised in 2011)]. Pod red. Belevskogo A.S. [Belevskiy A.S. (editor)]. Moscow: Rossiyskoe respiratornoe obshchestvo; 2012.

6. Lyubavina N.A., Makarova E.V., Menkov N.V., Mayorova L.V., Shonia M.L., Presnyakova N.B., Korolyeva V.V., Varvarina G.N., Novikov V.V. Clinical course of chronic obstructive pulmonary disease in dependence on smoking duration and the immune status of patients. Pul'monologiya 2013; 4: 52-55.

7. Kubysheva N.I., Postnikova L.B., Presnyakova N.B., Korolyova V.V., Kokushkov D.V., Karaulov A.V., Novikov V.V. Soluble ICAM-1 and ICAM-3 antigens in chronic obstructive pulmonary disease. Immunologiya 2009; 30(1): 55-56.

8. Lopez-Campos J.L., Calero C., Arellano-Orden E., Marquez-Martín E., Cejudo-Ramos P., Ortega Ruiz F., MontesWorboys A. Increased levels of soluble ICAM-1 in chronic obstructive pulmonary disease and resistant smokers are related to active smoking. Biomark Med 2012; 6(6): 805-811, http://dx.doi.org/10.2217/bmm.12.64.

9. Yin W., Ngwe E.C., Ghebrehiwet B., Rubenstein D.A. The combined effect of sidestream smoke and dynamic shear stress on endothelial cell inflammatory responses. Thromb Res 2015; 135(2): 362-367, http://dx.doi.org/10.1016/ j.thromres.2014.11.018. 
10. Scott D.A., Todd D.H., Coward P.Y., Wilson R.F., Odell E.W., Poston R.N., Matthews J.P., Palmer R.M. The acute influence of tobacco smoking on adhesion molecule expression on monocytes and neutrophils and on circulating adhesion molecule levels in vivo. Addict Biol 2000; 5(2): 195-205, http:// dx.doi.org/10.1080/13556210050003793.

11. Noguera A., Batle S., Miralles C., Iglesias J., Busquets X., MacNee W., Agusti A.G.N. Enhanced neutrophil response in chronic obstructive pulmonary disease. Thorax 2001; 56(6): 432-437, http://dx.doi.org/10.1136/thorax.56.6.432.

12. Schaberg T., Lauer C., Lode H., Fischer J., Haller $H$. Increased number of alveolar macrophages expressing adhesion molecules of the leukocyte adhesion molecule family in smoking subjects. Association with cell-binding ability and superoxide anion production. Am Rev Respir Dis 1992; 146 (5 Pt 1): 12871293, http://dx.doi.org/10.1164/ajrccm/146.5_Pt_1.1287.

13. Pace E., Ferraro M., Di Vincenzo S., Bruno A., Giarratano A., Scafidi V., Lipari L., Di Benedetto D.V., Sciarrino S., Gjomarkaj M. Cigarette smoke increases BLT2 receptor functions in bronchial epithelial cells: in vitro and ex vivo evidence. Immunology 2013; 139(2): 245-255, http://dx.doi. org/10.1111/imm.12077.

14. Lee I.-T., Yang C.-M. Inflammatory signalings involved in airway and pulmonary diseases. Mediators Inflamm 2013; 2013: 791231, http://dx.doi.org/10.1155/2013/791231.

15. McKeown S.J., Wallace A.S., Anderson R.B. Expression and function of cell adhesion molecules during neural crest migration. Dev Biol 2013; 373(2): 244-257, http://dx.doi. org/10.1016/j.ydbio.2012.10.028.

16. Abadier M., Haghayegh Jahromi N., Cardoso Alves L., Boscacci R., Vestweber D., Barnum S., Deutsch U., Engelhardt B., Lyck R. Cell surface levels of endothelial ICAM-1 influence the transcellular or paracellular $\mathrm{T}$-cell diapedesis across the blood-brain barrier. Eur J Immunol 2015; 45(4): 1043-1058, http://dx.doi.org/10.1002/eji.201445125.

17. Othumpangat S., Regier M., Piedimonte G. Nerve growth factor modulates human rhinovirus infection in airway epithelial cells by controlling ICAM-1 expression. Am J Physiol Lung Cell Mol Physiol 2012; 302(10): L1057-L1066, http://dx.doi. org/10.1152/ajplung.00365.2011.

18. Hafezi-Moghadam A., Thomas K.L., Prorock A.J., Huo Y., Ley K. L-selectin shedding regulates leukocyte recruitment. J Exp Med 2001; 193(7): 863-872, http://dx.doi.org/10.1084/ jem.193.7.863.

19. Zandvoort A., van der Geld Y.M., Jonker M.R., Noordhoek J.A., Vos J.T., Wesseling J., Kauffman H.F., Timens W., Postma D.S. High ICAM-1 gene expression in pulmonary fibroblasts of COPD patients: a reflection of an enhanced immunological function. Eur Respir J 2006; 28(1): 113-122, http://dx.doi.org/10.1183/09031936.06.00116205.

20. Lundberg A.H., Fukatsu K., Gaber L., Callicutt S., Kotb M., Wilcox H., Kudsk K., Gaber A.O. Blocking pulmonary ICAM-1 expression ameliorates lung injury in established dietinduced pancreatitis. Ann Surg 2001; 233(2): 213-220, http:// dx.doi.org/10.1097/00000658-200102000-00010.

21. Scott D.A., Palmer R.M. The influence of tobacco smoking on adhesion. Tob Induc Dis 2002; 1(1): 7-25, http:// dx.doi.org/10.1186/1617-9625-1-1-7.

22. Becker A., van Hinsbergh V.W.M., Jager A., Kostense P.J., Dekker J.M., Nijpels G., Heine R.J., Bouter L.M., Stehouwer C.D.A. Why is soluble intercellular adhesion molecule-1 related to cardiovascular mortality? Eur J Clin Invest 2002; 32(1): 1-8, http://dx.doi.org/10.1046/j.1365-2362.2002.00919.x.
23. Shavelle D.M., Katz R., Takasu J., Lima J.A., Jenny N.S., Budoff M.J., O'Brien K.D. Soluble intercellular adhesion molecule-1 (SICAM-1) and aortic valve calcification in the multi-ethnic study of atherosclerosis (MESA). $J$ Heart Valve Dis 2008; 17(4): 388-395.

24. Grothey A., Heistermann P., Philippou S., Voigtmann R. Serum levels of soluble intercellular adhesion molecule-1 (ICAM-1, CD54) in patients with non-small-cell lung cancer: correlation with histological expression of ICAM-1 and tumour stage. $\mathrm{Br} J$ Cancer 1998; 77(5): 801-807, http://dx.doi. org/10.1038/bjc.1998.130.

25. Alexiou D., Karayiannakis A.J., Syrigos K.N., Zbar A., Sekara E., Michail P., Rosenberg T., Diamantis T. Clinical significance of serum levels of E-selectin, intercellular adhesion molecule-1, and vascular cell adhesion molecule-1 in gastric cancer patients. Am J Gastroenterol 2003; 98(2): 478-485, http://dx.doi.org/10.1111/j.1572-0241.2003.07259.x.

26. Aaron C.P., Schwartz J.E., Bielinski S.J., Hoffman E.A., Austin J.H., Oelsner E.C., Donohue K.M., Kalhan R., Berardi C., Kaufman J.D., Jacobs D.R. Jr., Tracy R.P., Barr R.G. Intercellular adhesion molecule 1 and progression of percent emphysema: the MESA Lung Study. Respir Med 2014; 109(2): 255-264, http://dx.doi.org/10.1016/j.rmed.2014.10.004.

27. Lee J.S., Shin J.H., Choi B.S. Serum levels of IL-8 and ICAM-1 as biomarkers for progressive massive fibrosis in coal workers' pneumoconiosis. J Korean Med Sci 2015; 30(2): 140144, http://dx.doi.org/10.3346/jkms.2015.30.2.140.

28. Kanoh S., Rubin B. Mechanisms of action and clinical application of macrolides as immunomodulatory medications. Clin Microbiol Rev 2010; 23(3): 590-615, http://dx.doi. org/10.1128/CMR.00078-09.

29. Barnes P.J. Glucocorticosteroids: current and future directions. Br J Pharmacol 2011; 163(1): 29-43, http://dx.doi. org/10.1111/j.1476-5381.2010.01199.x.

30. Lyubavina N.A., Varvarina G.N., Makarova E.V., Menkov N.V., Belyaeva E.V., Ermolina G.B., Presnyakova N.B., Korolyova V.V., Filatova E.N., Kurnickov G.Yu., Novickov V.V. Serous content of adhesion soluble antigen as a marker of the chronic obstructive pulmonary disease progressing. Sovremennye tehnologii v medicine 2011; (1): 67-71.

31. Svirshchevskaya E.V., Matushevskaya E.V. Comparative analysis of efficacy and safety of fluoridated and chlorinated topical glucocorticosteroids Sovremennye problemy dermatovenerologii, immunologii $i$ vrachebnoy kosmetologii 2010; 3: 75-78.

32. Matera M.G., Cardaci V., Cazzola M., Rogliani P. Safety of inhaled corticosteroids for treating chronic obstructive pulmonary disease. Expert Opin Drug Saf 2015; 14(4): 533-541, http://dx.doi.org/10.1517/14740338.2015.1001363.

33. Barnes P.J. Corticosteroid resistance in patients with asthma and chronic obstructive pulmonary disease. J Allergy Clin Immunol 2013; 131(3): 636-645, http://dx.doi.org/10.1016/ j.jaci.2012.12.1564.

34. Huang J., Wan D., Li J., Chen H., Huang K., Zheng L. Histone acetyltransferase PCAF regulates inflammatory molecules in the development of renal injury. Epigenetics 2014; 10(1): 62-72, http://dx.doi.org/10.4161/15592294.2014.990780.

35. Oddera S., Silvestri M., Lantero S., Sacco O., Rossi G.A. Downregulation of the expression of intercellular adhesion molecule (ICAM)-1 on bronchial epithelial cells by fenoterol, a beta2-adrenoceptor agonist. J Asthma 1998; 35(5): 401-408, http://dx.doi.org/10.3109/02770909809048948.

36. Yamaya M., Nishimura H., Hatachi Y., Yasuda H., 
Deng X., Sasaki T., Kubo H., Nagatomi R. Inhibitory effects of tiotropium on rhinovirus infection in human airway epithelial cells. Eur Respir J 2012; 40(1): 122-132, http://dx.doi.org/10.11 83/09031936.00065111.

37. Yamaya M., Nishimura H., Nadine L.K., Ota C., Kubo H., Nagatomi R. Ambroxol inhibits rhinovirus infection in primary cultures of human tracheal epithelial cells. Arch Pharm Res 2014; 37(4): 520-529, http://dx.doi.org/10.1007/s12272-0130210-7.
38. Pang B., Hong W., West-Barnette S.L., Kock N.D., Swords W.E. Diminished ICAM-1 expression and impaired pulmonary clearance of nontypeable Haemophilus influenzae in a mouse model of chronic obstructive pulmonary disease/ emphysema. Infect Immun 2008; 76(11): 4959-4967, http:// dx.doi.org/10.1128/IAl.00664-08.

39. Khronicheskaya obstruktivnaya bolezn' legkikh [Chronic obstructive pulmonary disease]. Pod red. Chuchalina A.G. [Chuchalin A.G. (editor)]. Moscow: Atmosfera; 2008; 568 p. 